\title{
EDITORIAL
}

Received 2015-08-14

Revised 2015-08-21

Accepted 2015-08-25

\section{Ethics in Medical Research: Critical Steps For Researchers}

\author{
Ehsan Jangholi ${ }^{1}$, Soheila Yadollah-Damavandi ${ }^{1}$, Yekta Parsa ${ }^{1 凶}$ \\ ${ }^{1}$ Young Researchers and Elite Club, Islamic Azad University, Tehran Medical Sciences Branch, Tehran, Iran.
}

$\mathrm{E}$ hics, human nature and inherent characteristics of the origin of human behavior have the most profound influence and impact on the field of human behavior. Ethics is divided into several branches including medical ethics, bioethics and research ethics. Medical ethics is a subdivision of philosophy or moral that attempts to elaborate the correct and incorrect performance in the field of medicine and health care through philosophical analysis. Bioethics is a part of applied science which uses ethical principles for solving present and foreseeable problems in medicine and biology. However, in this debate we are concerned with ethics in medical research [1]. Regarding the development of medical research in various fields such as human and animal research, special thought in these areas will be necessary. Medical world has a painful history because of disregard for ethical issues. Unfortunately, much evidence of this can be found in all countries of the world. For example, transfusions of infected blood to 40 patients in Robert Koch Institute to investigate their effect or implanting sand and glass into the wounds of patients to evaluate the effects of sulfonamides on wound infection [2,3].

Following the disclosure of immoral activities of the Nazi physicians at the end of World War II, all research centers adopted ethical research criteria along with training and organizational preparations to prevent a repetition of similar catastrophes [4]. Prosecution of those

\section{GMJ}

2013 Galen Medical Journal

Fax: +98 7312227091

PO Box 7461686688

Email:info@gmj.ir doctors who participated in immoral acts showed that the researchers especially in the medical field should be bound to respect the governing conventions. This led to the adoption of the "Nurember Declaration" in 1947. At the XVIIIth meeting of the World Medical Association (WMA) in Helsinki, a set of rules known as the 'First Helsinki Declaration' was adopted for the guidance of all professionals in this field [5].

At its twenty-ninth session, WMA amended the previous rules and introduced the 'Second Helsinki Declaration' to be followed in medical research [6].

Given a brief attention to the research process, we need to pay attention to ethical issues in all steps that are described below:

\section{Selection of Research Topic}

1. Accepting research topic by a population studied and the research priorities for the target population

1. Considering beliefs, practices and traditions of the society

3. Avoiding derogatory and offensive expressions

4. Fair presentation of other data

\section{Review of Documents}

1. Adhering to honesty and trustworthiness

2. Impartiality of researchers

3. Mentioning the names of other scientists who have done research in the field

\footnotetext{
Correspondence to:

Yekta Parsa, Young Researchers and Elite Club, Islamic Azad University, Tehran Medical Sciences Branch, Tehran, Iran.

Telephone Number: (+98) 21-22006660

Email Address :yektaparsa@gmj.ir
} 


\section{Avoiding of invalid references}

\section{Study Design}

1. Using the latest research methods for obtaining results

2 . Non-exclusive use in ways that are consistent with the objectives of research

\section{Human Resources and Management}

1. Securing the well-being of team members and avoiding inconveniencing them

2 . Preventing the abuse of individuals or community members under study by the research group

3. Carefully using funds and resources

Analysis, Reporting and Publication of Results

1. Adhering to the integrity of data analysis and avoiding distortion of results

2 . Keeping confidential the information collected from studied subjects
3. Respecting individuals and society when discussing and interpreting the results

4. Sharing results with officials at various levels

Unfortunately, there is not any information about the status of attention and respect to the ethical issues in medical research among Iranian researchers. However, in the study conducted by Larijani et al., the result showed a deviation of research ethics in Iran higher than the global index [1].

The incidence of new ethical issues coincided with the advancement of medical science in all aspects including diagnosis, treatment and prevention which affect the mood and mental of patients in many diseases. It is necessary to give more attention to ethical issues.

Keywords: Ethics; Medical; Research; Journalism; Researcher

\section{References}

1. Larijani B, Zahedi F, Malek-Afzali H. Medical ethics in the Islamic Republic of Iran. East Mediterr Health J. 2005;11(56):1061-72.

2. Larijani B. Ethic in medical research. 2th ed. Tehran: Baray-e-Farda publication; 2012.

3. Raum E. World War II: An Interactive History Adventure: Capstone; 2009.

4. Roth JK. REVIEW: ARNO MAYER'S
HOLOCAUST REVISIONS. Holocaust and Genocide Studies. 1990;5(2):217-21.

5. Vollmann J, Winau R. Informed consent in human experimentation before the Nuremberg code. BMJ. 1996;313(7070):1445-9.

6. Goodyear M, Krleza-Jeric K, Lemmens T. The Declaration of Helsinki. BMJ. 2007;335(7621):624-5. 